\title{
EL TRATADO DE ARQUITECTURA DE LEONCE REYNAUD EN MÉXICO
}

XAVIER MoYsSÉN

La teoría en cuanto a un sistema de ideas respecto a la arquitectura, no ha encontrado en México campo propicio de meditación, ni por parte de los filósofos ni de los practicantes de la misma; salvo el caso del arquitecto José Villagrán García (1901-82), quien a lo largo de su vida profesional elaboró una serie de principios, si no del todo originales sí bien estructurados, para llegar a ordenar lo que se ha dado en llamar "la teoría de Villagrán", a la cual, juzgada críticamente, hay que situar frente a sus propias obras arquitectónicas; en otras palabras, es necesario estudiar los cuatro principios fundamentales de su teoría con la práctica profesional que desarrolló en buena parte de su existencia, para constatar así hasta qué punto existe la congruencia. ${ }^{1}$

Un arquitecto con una formación filosófica sólida fue Alberto T. Arai (1915-59); a él se debe un número considerable de escritos que exponen sus meditaciones sobre el arte de la construcción; sus ideas guardan relación con la postura nacionalista que adoptó. Es probable que el estudio metódico de sus escritos ofrezca los principios de una teoría que no alcanzó a desarrollar.

Durante la prolongada presidencia del general Porfirio Díaz, la cual se significó por su abierta simpatía hacia la cultura francesa, tres tratadistas galos tuvieron considerable importancia en la formación que se daba a los estudiantes de la Escuela de Arquitectura, incorporada a la Academia de San Carlos. Ellos fueron Léonce Reynaud, autor, como Louis Cloquet, de un Traité D'Architecture, y Julien Gaudet, autor de Elements et Théorie de L'Architecture; las obras de estos teóricos fundamentaron principalmente el conocimiento y la práctica de los ingenieros y arquitectos mexicanos, independientemente de si los últimos estudiaran o no, en la famosa École des Beaux Arts de París. Es oportuno recordar que en esa época estaban ligadas las carreras de arquitecto e ingeniero, y que éstos tenían

${ }^{1}$ En realidad José Villagtán Gatcía no publicó en forma sistemática sus reflexiones teóticas; las dictó más bien en los cursos de Teoría de la Arquitectura que atendía en la Escuela Nacional de Arquitectura de la UNAM; de esos cursos salieron escritos por él los textos que conforman su Teoría, publicada como tal en 1964 y reimpresa en una tercera edición de 1987, como número extraordinario de los Cuadernos de Arquitectura y Conservación del Patrimonio Artístico, INBA. 
una importancia mayor sobre aquéllos. La influencia de los tratados anotados se prolongó más allá de la segunda década de este siglo; no fue casual que en 1942 José Villagrán Garcia haya publicado la versión que hizo de la Introducción del Tratado de Reynaud. ${ }^{2}$ Ahora bien, las obras de los autores citados, editadas en lujosos volúmenes, alcanzaban precios que, como sucede siempre, quedaban fuera de las posibilidades adquisitivas de los estudiantes, lo cual dio lugar a que el Tratado de Léonce Reynaud fuera traducido y compendiado para su publicación por el ingeniero Jesús Galindo y Villa, personaje interesado en las cuestiones de arquitectura.

Jesús Galindo y Villa (1867-1937) fue un digno representante del saber erudito de su época. Su educación básica tuvo un marcado sello francés. Ingeniero de profesión, no obstante practicó diversas actividades durante su existencia, desde las relacionadas con la docencia en distintas instituciones hasta las de carácter público administrativo, como Regidor de la ciudad de México. Figuró también como miembro destacado de varias sociedades culturales, como la de Geografía y Estadística, la Astronómica de México, la Antonio Alzate y la Academia Mexicana de la Historia. Con la pluma fue prolifico; publicó, aparte sus constante colaboraciones periodísticas, trabajos relacionados con la arqueología, la historia y la geografía. En relación con el arte ocupó la dirección del Conservatorio de Música, y en años difíciles estuvo al frente de la Academia Nacional de Bellas Artes. ${ }^{3}$ Un viaje a España en 1892, con fines oficiales, le permitió visitar diversos países y conocer las obras artísticas que poseían. Ignoro hasta dónde llegaban sus conocimientos reales sobre el arte edilicio y no he encontrado noticias referentes a su profesión de ingeniero; en consecuencia, nada sé sobre si llegó, o no, a construir obra alguna. ${ }^{4}$

\footnotetext{
2 Está publicada en el No. 10 de la revista Arquitectura, pp 24-32. México, julio de 1942.

${ }^{3}$ Respecto a su gestión en la Academia (1912-13), Fausto Ramírez ofrece amplia in formación y oportunos comentatios en "Tradición y modernidad en la Escuela Nacional de Bellas Artes, 1903-1912". Véase Las Academias de Arte, pp. 207-59. México, UNAM, 1985.

${ }^{1}$ Para una información más amplia sobre sus actividades intelectuales, consúltese la Noticia de diversos escritos de Jestís Galindo y Villa, director de la Academia Nacional de Bellas Artes, profesor del Museo Nacional de Arqueología, Historia y Etnologia, pubticados de 1887-1912 México, 1913. Otras noticias ofrece Dolores Galindo y Villa, en la segunda edición del libro de su padre, Polvo de Historia, México, Patria, 1954. Un breve comentario en relación con la arquitectura y Galindo y Villa, en el estudio de Ramón Vargas Salguero "Las reivindicaciones históricas en el funcionalismo socialista"; véase "Apuntes para la histotia y crítica de la arquitectura mexicana del siglo XX: 1900-1980" Cuadernos de Arquitectura y Conservación del Patrimonio Artístico, vol. I, pp. 75-76 Nos. 20-21 México, INBA, 1982
} 
De los tratadistas franceses de arquitectura del siglo XIX, dos han trascendido por la vigencia de sus proposiciones teóricas, por el criterio racional con que supieron ver la importancia del arte de construir, aplicando tanto los nuevos métodos como los materiales que terminarían por modificar radicalmente la arquitectura en el presente siglo. Hoy día se les estudia y se les otorga el valor que en un momento determinado les fue negado; ellos son: Léonce Reynaud (1805-80) y Eugene Viollet-Le-Duc (1814-79). Diversos estudios se han publicado en favor de su reivindicación; de ambos se ocupó ampliamente Peter Collins en su imprescindible libro Ideales de la arquitectura moderna, ${ }^{5}$ y en fecha reciente en México el arquitecto Ramón Vargas Salguero ha hecho una revaloración de los Entretiens de Viollet-Le-Duc. ${ }^{6}$

Reynaud, aunque tuvo un breve paso por la École des Beaux Arts, en verdad debió su formación de ingeniero y arquitecto tanto a la École des Ponts et Chaussées como a la École Polytechnique. De un ciclo de conferencias que dictó en la última institución, entre 1848-49, nació su famoso Tratado, que fue, a juicio de Collins, "el curso sobre teoría arquitectónica más completo y puesto al día que se podía encontrar en el mundo"? La primera edición apareció en 1850 .

El Traité D'Architecture de Léonce Reynaud en sus diversas ediciones se publicó en cuatro volúmenes; los dos primeros, de formato menor, están dedicados a los textos, en tanto que los restantes, de mayor tamaño, contienen las láminas que ilustran el tratado con una magnífica selección de ejemplos al caso. ${ }^{8}$ En un extenso párrafo que a continuación transcribo, Collins hace una justa apreciación de la importancia del autor y su obra:

El tratado de Reynaud está dividido en tres partes principales. La primera parte trata de los materiales estructurales y del análisis científico de sus propiedades; la segunda parte trata de los elementos arquitectónicos (es decir, de columnas, vigas, vanos, bóvedas, etc., considerados tanto desde el punto de vista estático como estético); la última parte trata de la composición, es decir, de los varios tipos de edificios, y del modo como los diferentes programas de exigencias se llevaron a cabo hasta el tiempo en que escribió. A Reynaud, científico por temperamento (el subrayado es mío), le costaba trabajo menospreciar el contenido de la creatividad arquitectónica; pero su método era la quintaesencia del racionalismo, como aclara en su prólogo: "ninguna forma - dice- se

5 Barcelona, G. Gili, 1970

'En el número 57 de estos Anales, pp. 189-207. México, UNAM, 1986.

7 Op. Cit., pp. 196-97.

${ }^{8}$ Gtacias al arquitecto Carlos Chanfón Olmos, he tenido a mi alcance la edición de Dunod, París, 1875 
define sin referirla a los aspectos racionales que motivaron su origen" y define la arquitectura como "un arte emintentemente racional". Sin embargo, añade también que la arquitectura "exige una gran imaginación". Insiste asimismo en la necesidad de una "completa armonía entre forma y función", y en que así como existe una relación íntima entre forma y función en los seres naturales (por lo que "el exterior" es el resultado de la composición interior"), así en la arquitectura la forma debe ser el resultado de satisfacer un fin con orden y simplicidad, no admitiendo nada más que lo fundado en exigencias reales.

Jesús Galindo y Villa se dio a la tarea de traducir el Tratado de Arquitectura movido por varios propósitos; doy por sentado que el tratado le era familiar y de ahí su ánimo primordial para acometer una traducción compendiada del mismo, la que publicó como obra propia bajo el título de Apuntes de órdenes clásicos y composición de arquitectura, ${ }^{10}$ lo cual se justifica en cierta forma si se consideran las modificaciones que hizo al texto de Reynaud, más las aportaciones que introdujo en favor de los estudiosos mexicanos. Sus propósitos están expuestos en una introducción dedicada Al lector.

Puesto que carezco de noticias sobre la formación profesional de Galindo y Villa, voy a dar por hecho que realizó estudios de ingeniero y arquitecto, conforme a lo establecido desde 1857 en que Javier Cavallari organizó los estudios en la vieja Academia de San Carlos, uniendo en una sola las carreras de ingeniería y arquitectura; él obtuvo el título de ingeniero con el cual fue conocido. Sin embargo, de la lectura de la introducción a sus Apuntes, se comprende que tenía en mayor estima la profesión de arquitecto que no así la de ingeniero. Principia anotando que "en México es casi desconocida la importancia de los estudios arquitectónicos; al grado de que se tiene errónea idea sobre la misión del Arquitecto. Creencia general es, que el constructor de edificios ...tan sólo ha de ser perito en la ciencia matemática; y que para que la fábrica resulte bien presentada, no se requiere más que de buen gusto y cierta habilidad". Líneas adelante anota convencido que "a quien de hecho y de derecho indisputable com" pete la construcción de toda clase de edificios, ya particulares, ya de utilidad pública, es al arquitecto, más que a ninguna clase de ingenieros. ..",11 con lo que asumió una postura bien definida frente a éstos.

${ }^{9}$ Op. Cit, p. 197. La extensa cita permite comprender la trascendencia de Reynaud hasta el siglo actual, como se anotó líneas atriba Lo que dijo respecto a la forma y la función, no está lejos del concepto de Louis H. Sullivan (1856-1924) de que la forma sigue a la función, concepto que supieron aprovechar los funcionalistas

${ }^{20}$ El libro fue publicado por la Secretarfa de Fomento en 1898

$11 \mathrm{Op}$ Cit, p. V. 
En otra parte escribe, para explicar las razones que le llevaron a publicar sus Apuntes, que no sólo los "Ingenieros de Caminos, Puentes y Canales, llamados genéricamente Civiles, los Militares y aun los mismos Industriales", se creen en el derecho de construir como los arquitectos, sin poseer como éstos los "conocimientos artísticos"; mas no se crea que con la sola posesión de tales conocimientos, bastaba al saber de los arquitectos; a ellos les exigía Galindo y Villa que no descuidaran las bases racionales requeridas para lograr una buena construcción. Líneas adelante anota, con propósitos que por sí solos se explican, la falta de libros especializados que en mucho ayudarían a aquellos que sin conocimientos teóricos se abocan a las actividades arquitectónicas.

La carencia en México de textos especializados en el arte edilicio fue la razón mayor que le movió a la empresa del libro; tal razón, asentó, "me ha subyugado a publicar estos Apuntes, extractados en su mayor parte del Traité d'Architecture del maestro Leoncio Reynaud, de texto en nuestra Escuela Nacional de Bellas Artes", y añade, teniendo en principal cuenta a los estudiantes, que debido al "costo elevadísimo de la obra no permite adquirirla sino a muy contados alumnos; razón por la cual no sólo se les dificulta el estudio teórico en el discurso de los años respectivos, sino también los exámenes de Órdenes de Composición". ${ }^{12}$

Jesús Galindo y Villa se presentaba siempre con el título de ingeniero, por ello sorprende la posición de censura que adoptó en contra de los ingenieros, que, como se ha dicho líneas atrás, formaban desde 1857 un solo gremio profesional con los arquitectos. Para la época en la que dispuso sus Apuntes, los ingenieros, sobre todos los militares, tenían a su favor todas las de ganar, para ellos eran los mejores contratos. La situación no tardó en generar el descontento de los arquitectos, quienes, como se ve, contaban con la simpatía de Galindo y Villa. En 1895 se presentaron ante el Cabildo de la Ciudad de México, varios arquitectos solicitando que se concedieran las licencias para la construcción de edificios sólo con las autorizaciones de arquitectos titulados. Argumentaban "los solicitantes en que (su profesión) constituye una carrera especial, conteniendo un conjunto de conocimientos que no poseen los ingenieros civiles y militares y además en que desde la Ley de Instrucción Pública de 1861, quedó elevada la arquitectura a la categoría de una profesión que demandaba forzosamente título para su ejercicio". ${ }^{13}$ En un memorable discurso ante el Presidente Díaz, en 1900, Nicolás Mariscal hizo ante la máxima

12 Op. Cit, p VI.

${ }_{13}$ Documento del Archivo del Ayuntamiento, localizado por la investigadora María Concepción Amerlinck, quien lo estudia para su publicación. 
attoridad del país una enérgica defensa de la profesión de los arquitectos, condenando "la confusión que produjo el extravagante título mixto de ingeniero-arquitecto". Se justifica reproducir una parte de cuanto dijo en favor de la actividad que practicaba:

...hay en el público, y aún en el público ilustrado, personas que no prestan la debida atención a lo que es la arquitectura en sí misma y del género de conocimientos y de educación que requiere el arquitecto. ¡Cuántos hay que creen que la arquitectura es una voz sinónima de ingeniería! ¡Cuántos que creen que la arquitectura es como la mecánica, la minería, los medios de transporte; etcétera, es decir, una rama de la ingeniería civil! iy cuántos en fin, llegan a asegurar que es ella como la artillería una rama de la ingeniería militar ${ }^{14}$

Un sólido conocimiento del idioma francés debía poseer Galindo y Villa para arriesgarse a traducir el Tratado de Reynaud y, lo que es más, a compendiarlo parcialmente, sin falsear gravemente el sentido de la obra. La versión incompleta que hizo, la ordenó en cuatro partes, en las cuales, sin alejarse del todo del orden del original, refundió el contenido de lo que le interesaba, suprimiendo aquello que consideró carente de interés para sus propósitos. Un solo ejemplo: los dos tomos que contienen el extenso texto del Tratado están ordenados por libros y éstos, a su vez, por capítulos. Del libro primero, del primer tomo, suprimió los dos capítulos iniciales, no obstante su importancia, pues están dedicados a los materiales de construcción, descripción de los mismos y su resistencia. Del libro segundo suprimió únicamente los dos capítulos que lo abren, en tanto que del siguiente, que se ocupa de los soportes aislados con entablamento, hizo la adaptación pertinente y con ello inició el texto de sus Apuntes.

Las cuatro partes en que dividió Galindo y Villa su libro se ocupan: la primera del "estudio de los Órdenes Clásicos", la segunda la dedicó a "La Composición"; la tercera a las "principales partes de los Edificios", en tanto que la última "trata de los edificios propiamente dichos", concediendo aquí una enorme importancia a los religiosos. Al final tuvo el cuidado prudente de anotar que los Apuntes, "como su propio nombre lo señala, no son un tratado, ni pretenden tan alto título: son una modesta ayuda-memoria..." $1 \pi$ Para los fines que perseguía con la adaptación del Tratado, acudió a otros autores, como Eugène Viollet-Le-Duc y los mexicanos Antonio García Cubas y Manuel G. Revilla.

14 El discurso se reprodujo en El arte y la ciencia, vol. II, números 8-10. México, noviembre de 1900 No es ocioso recordar aquí que Félix Díaz, hijo del dictador, era ingeniero militar

is Op cit, $p \mathrm{XI}$ 
Jesús Galindo y Villa no se olvidó de incluir en sus Apuntes la arquitectura de su país, incorporándola así a la del Viejo Mưndo tratado por Reynaud. De la época prehispánica se ocupó de las pirámides de Teotihuacan, aprovechando lo escrito por García Cubas. En el apéndice que incluyó, reprodujo el estudio de Francisco M. Rodríguez sobre "La habitación privada de los aztecas en el siglo XVI". La parte referente a los edificios religiosos, la dedicó principalmente a las catedrales de México y Puebla, ofreciendo, además, "otros datos sobre nuestra arquitectura religiosa" " En la época en que publicaba sus Apuntes (1898) una gran novedad para México la constitufa el edificio de la Penitenciaría del Distrito Federal, obra de Antonio M. Anza; a ella dedica elogiosamente extenso comentario. ${ }^{17}$

Una lámina con varios ejemplos arquitectónicos ilustra al final la obra que realizó el ingeniero Galindo y Villa; la lámina dibujada por él es la parte más censurable del libro, pues le faltaba sensibilidad con la pluma y tal parece que carecía de conocimientos para la práctica del dibujo de arquitectura; no obstante, debía conocer bien los magníficos grabados que ilustraban los libros de procedencia francesa.

La importancia del Tratado de Arquitectura de Léonce Reynaud sobre las obras de otros autores fue fundamental en la Escuela Nacional de Arquitectura; $\tan$ lo fue que ello motivó a Jesús Galindo y Villa para emprender su traducción, arreglo y compendio con fines prácticos, en buena medida en beneficio de los estudiantes y de aquellos a quienes él consideraba ignorantes en el arte de la arquitectura. Fuera del esfuerzo de Galindo y Villa, no tengo noticias de la existencia de otro trabajo similar. Habría que esperar a que corrieran los años para que se diera el caso de José Villagrán García, simpatizante como se ha visto del tratadista francés.

Muchos arquitectos se ocupan, en las aulas universitarias, de la ensenanza de la teoría de la arquitectura. ¿En qué nivel de originalidad? Sólo ellos lo saben; mas cabe pensar en que algo personal deben aportar conforme a sus propias experiencias profesionales y sus lecturas; sin embargo, no es mediante la escritura como han dejado constancia de su saber; sus palabras se quedan en el ámbito de la cátedra y en la recepción de quienes con provecho les escucharon. Como quiera que sea, los Apuntes debieron cumplir su finalidad: mantener vivo el pensamiento de Reynaud entre los arquitectos mexicanos, y obtener del mismo los conocimientos necesarios para hacer una buena arquitectura

${ }^{16}$ Apunies, pp. 217-224

17 Ibidem, pp 282-290 